Komal Mishra, ${ }^{1 *}$ Nandita Chaube ${ }^{2}$

\title{
Effect of dance movements on stereotype and repetitive behaviours of cases with autism spectrum disorder
}

\author{
'Student, M.Sc. Clinical Psychology, Institute of Behavioural Science, Gujarat Forensic Sciences University, INDIA \\ ${ }^{2}$ Assistant Professor, Institute of Behavioural Science, Gujarat Forensic Sciences University, INDIA \\ *email: nandichaubelagmail.com
}

DOI: 10.2478/gp-2020-0010

Received: 27 May 2019; Accepted: 19 April 2020

\begin{abstract}
Objective: The objective of the study was to observe the effects of dance movements on stereotypical and repetitive behaviours of children diagnosed with autism spectrum disorder (ASD).

Method: The sample consisted of 5 patients within the age range of 9 to 16 years. Of the pool of 15 patients, 5 were lying in the range of moderate autism spectrum disorder with a higher score on stereotypical and repetitive behaviours. There were three male and two female patients. The cases were regularly coming to the day care centre of a hospital located in the southern part of India. Participants were assessed by Autism Spectrum Screening Questionnaire (ASSQ) and BASIC-MR Part-B. Dance movement intervention was planned for these five cases.

Results: Pre-and post-test scores were taken to observe the effects of dance movements on their behaviours. Fifteen sessions with a duration of 60 minutes per session were given. The results showed improvement in the repetitive behaviour in the sample, in which of these five, three showed greater improvement.

Conclusion: Hence, the result shows that dance movement could be used as an effective method to improve stereotypical and repetitive behaviour in children diagnosed with ASD.
\end{abstract}

\section{Keywords}

Autism, dance movement, stereotyped and repetitive behaviour

\section{INTRODUCTION}

Autism spectrum disorder (ASD) is a complex neurodevelopmental disorder characterised by abnormalities in social behaviour, language, communication and behaviour (Mash \& Wolfe, 2013; Cohen \& Walkmar, 1997)) and unusual or stereotypical behaviours and interests (Johnson, Myers, \& the Council on Children with Disabilities, 2007). Autism is defined as spectrum disorders because its symptoms are observed with many different clusters and degree of severity (Lord, Cook, Leventhl, \& Amaral, 2000). Majority of ASD cases even being different on IQ, gender, and socio-economic status show common essential symptoms (Mayes \& Calhoun, 2011) that widely vary in the intensity (Jones \& Klin, 2009).

Such cases are characteristically engaged in unusual patterns of behaviour having confined range of restricted interests that are very common to such patients. These cases experience a strong desire to maintain routines and have a strong resistance to change (Carr, 1999). They often repeatedly perform stereotyped motor acts such as hand clapping or flapping or peculiar finger movements. Some of them present with self-injurious behaviours such as biting or striking themselves or banging their heads, but this is more likely to be presented with severe or profound mental retardation (MR) but is also observed in children with autism without MR (Kay \& Tasman, 2006). There are many cases in which children with autism mild levels of MR (Hoeksema, 2004). They often have poor performance in measures of intellectual ability with $29 \%$ of mild to moderate intellectual impairments (Fombonne, 1999).

Neuropsychological explanations of these unusual and stereotypical behaviours pose towards the dysfunction of medial frontal lobe regions and related limbic structures. These motor disturbances resemble neurological symptoms of adult patients with dysfunction of the basal ganglia and associate regions of temporal lobe (Damasio \& Maurer, 1978), 
which is proved by the further studies demonstrating increased frontal lobe functions in children with autism (Ozonoff, 1995; Ozzonoff et al, 1994; Prior \& Hoffman, 1990). Some researchers argued that autism is a disorder of prefrontal cortex (Minshew \& Godlstein, 1993; Rogers \& Pennington, 1991). But others explained these behaviours in terms of combination of social cognitive and executive functions that may be linked to frontal brain areas. However, autopsy studies have revealed reduced neuronal size and increased cell packing destiny in the hippocampus, amygdala and adjacent limbic regions (Bauman \& Kemper, 1994). These structures, especially the amygdala, mediate basic brain functions that may be required for skills in which persons with autism are typically impaired, such as motor imitation (Dawson, Meltzoff, Osterling \& Rinaldi, 1998; Osterling \& Dawson, 1994; Smith \& Bryson, 1994). In other studies, motor functions amongst patients with autism are attributed to granule cell loss (Courchesne, 1989).

Behaviour-based non-pharmacological treatments have demonstrated a significant reduction in these challenging behaviours in controlled studies (Smith, 1993; Koegel \& Kegel, 1996; Bregman \& Gerdtz, 1997) but majority of studies have been performed on the co-morbid conditions, presenting with intellectual disabilities (Oliver, 1995).

As most of the treatments of ASD are symptom directed, they require diverse treatments simultaneously. Common behavioural problems of such cases are aggression, selfinjurious behaviours and interfering repetitive behaviours (Kay \& Tasman, 1996) and also developing therapeutic relationship (Porter, 2012). Physical exercise has been shown to decrease the repetitive behaviour in children diagnosed with ASD and for improving the cognitive functioning across the whole life time (Hanley et al., 2011). Mirroring approach is said to be effective in such cases where the movements are reflected on either side, therapist or the case. This is tested by the quality of the reflexion (Eberhard-Kaechele, 2012; McGarry \& Russo, 2011). The positive results are due to fact that movement and exercise can spark the growth of new brain cells and facilitate learning (Ratey, 2008).

Majority of researchers focused on the development of interaction skills (Kestenberg, 1995; Keysers, 2011) and social skills (Oberman \& Ramchandran, 2017; Koehne et al., 2015) as an early intervention with children (Martin, 2014). However, focused studies pertaining to improvements in the repetitive and stereotypical behaviour are less evident. Dance movement intervention in cases of ASD is a well-researched phenomenon in psychiatry or psychology, but its impact on stereotypical and repetitive behaviours is hardly explored. Furthermore, the studies are either on adolescents (Teixeira-machado, 2015) or on other aspects of autism (Inlayson, Fitzgerald, Murphey, \& Brown, 2015). For this reason, focused studies are required to draw attention of researchers and practitioners to improve these symptoms. Hence, the current study was planned with an aim of assessing the effectiveness of dance movements on stereotypical and repetitive behaviours of children with ASD. Keeping in view these concerns, the current study aims to evaluate the effectiveness of dance movement on stereotypical and repetitive behaviour of children diagnosed with moderate ASD. It was hypothesised that dance movement will bring positive change in stereotypical and repetitive behaviour of children diagnosed with ASD.

\section{METHODS}

Sample

The sample consists of five patients (three male patients and two female patients) with autism aged between 9 and 16 years from a special education school in Hyderabad city. These 5 patients selected from a pool of 15 patients were lying in the range of moderate symptoms with a higher score on stereotypical and repetitive behaviours.

Pre- and post-test scores were taken to evaluate the effects of dance movements on their behaviours. Only moderate ASD cases who showed no intellectual or any co-morbid disorder were included in the study. These children had repetitive behaviours such as hand flapping, rocking body, head nodding, thumb sucking, making peculiar sounds, shaking body, swinging round and round, and tip toe walking. All the participants had functional upper and lower limbs. Purposive sampling was used for the collection of sample.

These cases were selected because children with mild symptoms generally do not require much support but those with moderate level of symptoms require guided intervention. The moderate range of autism is more elaborated with less-specific boundaries; it increases the scope of intervention overall.

\section{Tools Used}

\section{Autism Spectrum Screening Questionnaire, ASSQ (Gillberg, 1993):}

The ASSQ was developed as a screening instrument for high-functioning patients with autistic disorders. This test was designed to assess children aged 7-16 years with normal intelligence to mild MR. The ASSQ consists of 27 items rated 
on a 3-point scale $(0,1$, or 2; 0 indicates normality, 1 some abnormality, and 2 definite abnormality). Test-retest reliability of this scale was found to be 0.96 in case of parents' reports and 0.94 in case of teachers' reports.

Validity scores with two general measures of psychopathology were 0.75 and 0.58 for parents' reports and 0.77 and 0.70 with teachers' reports. The ASSQ scores were significantly different amongst three groups of children with ASD, attention-deficit and disruptive disorders and learning disorder from children with ASD from children with attention-deficit and disruptive disorders, and learning disorder with a sensitivity of $62 \%$ and a specificity of $90 \%$ for parent reports and with a sensitivity of $70 \%$ and a specificity of $91 \%$ for teacher reports.

\section{Behavioural Assessment Scales for Indian Children with Mental Retardation (BASIC-MR) Part B (Reeta Peshawaria, S. Venkatesan, Mohapatra \& Menon, 1990):}

The Behavioural Assessment Scales for Indian Children with Mental Retardation (BASIC-MR) Part B has been designed to elicit systematic information on the current level of behaviours in school-going children with mental impairment. The scale is suitable for mentally impaired children aged between 3 and 16 (or 18) years. However, the teacher may find the scales useful for even older severely retarded individuals. The scale is relevant for behavioural assessment and can also be used as a curriculum guide for programme planning and training based on the individual needs of each mentally impaired child. The items included in part B of the scale helps to assess the current level of behavioural problem in the child. The BASIC-MR Part B consists of 75 items grouped under 10 domains (Violent and destructive behaviours, Temper tantrums, Misbehave with others, Self injurious behaviours, Repetitive behaviours, Odd behaviours, Hyperactive behaviours, Rebellious behaviours, Antisocial behaviour and Fears). The test-retest reliability of this tool was found to be 0.68 . The construct validity was established by measuring the significant difference between the mean scores at pre- and post-test levels. This change was found to be statistically significant $(\mathrm{p}<0.001)$.

\section{Procedure}

The topic was approved by the Institutional Review Board of the institute. The letter of approval from the institute was shown to the head of the special education school and the final permission for data collection was obtained. Cases were identified after consulting with the psychiatrists and the selection was performed after checking the records. Afterwards, the parents were informed and the consent was obtained from the parents of the children. Pre- and post-test assessments in A-B-A sequence were performed done through BASICMR Part B and ASSQ screening tool, where A was baseline assessment, $\mathrm{B}$ was intervention and $\mathrm{A}$ was re-assessment. This intervention plan consisted of 15 sessions (1 hour per session on a daily basis). One week of regular observation was performed followed by 15 sessions and then again 1-week observation. Techniques used to ensure participation in dance activity were prompting, modelling, reinforcement and instructions in the intervention of dance movement.

\section{Session Details}

The dance movement therapy combines creative expression through dance and movement, the use of music, play and body awareness exercises. The below-mentioned parts are included in preparing the dance movement therapy session. Group sessions are often divided into five parts:

1. Opening ritual (saying hello and good morning to each other).

2. Check-in (forming a circle to get adjusted with everyone and then walking hand in hand with any partner)

3. Body warm-up (exercising. walking in, sports and some hand movement exercises).

4. Actual session with music: Rhymes and poems of different types were played and dance steps including jumping, zigzag movements, clapping and touching the ground, feet and shoulders were involved

5. Closing ritual (saying goodbye to everyone).

\section{RESULTS}

\section{Progress Through The Sessions}

\section{Case 1:}

This 9-year-old boy had much suffering with the head nodding, rocking body, making peculiar sounds and shaking body. In the initial sessions of interventions, he was quiet observant of others and did not follow any of the instructions. No response was generated from his side. He was very aggressive and stubborn by his behaviour and did not try to participate in the activities and made any movements. He used to stand still in the sessions. After the fourth session, he gradually started getting involved in the activities and started enjoying the music and dance. In the eighth session, he himself started doing activities on single instruction and making little movements of dance on music. From 10th session onwards, he started doing opening rituals and passing smile. The 


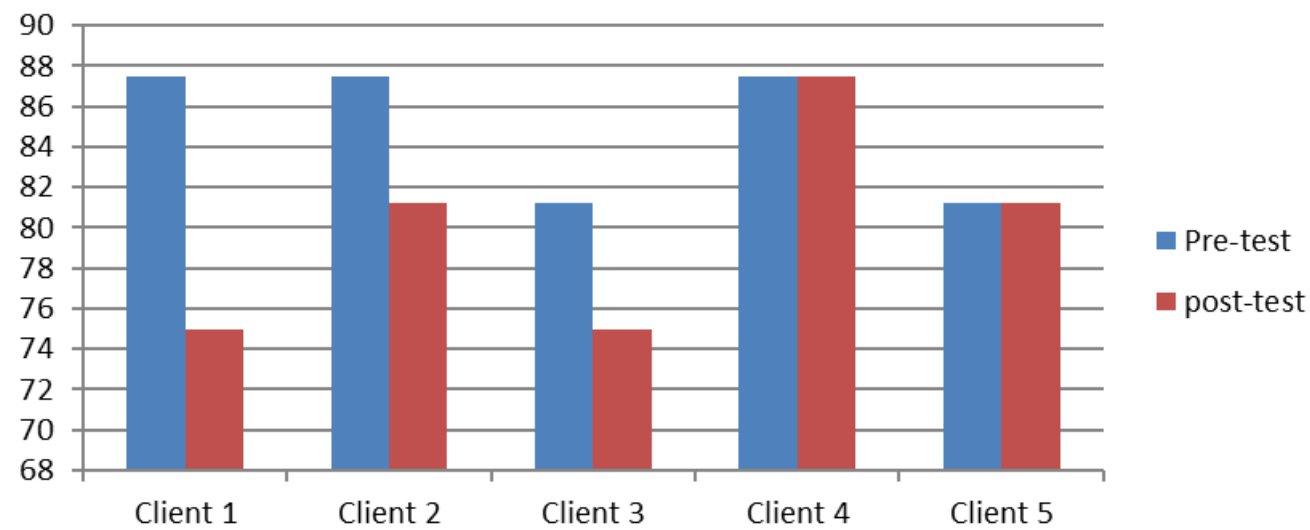

Figure 1. Graphical representation of Pre- and post-test scores of BASIC-MR Part B (subscale for repetitive behaviour)

Table 1. Case-wise scores of Autism Spectrum Screening Questionnaire (ASSQ) and other details

\begin{tabular}{|c|c|c|c|}
\hline Cases & Age (years) & Gender & Autism Score \\
\hline Case 1 & 9 & Male & 28 \\
\hline Case 2 & 10 & Male & 33 \\
\hline Case 3 & 15 & Female & 30 \\
\hline Case 4 & 9 & Male & 37 \\
\hline Case 5 & 11 & Female & 35 \\
\hline
\end{tabular}

Note: A score above 20 indicates symptoms of autism spectrum disorder

Table 2. Pre- and post-test scores of BASIC-MR Part B (subscale for repetitive behaviour]

\begin{tabular}{|c|c|c|}
\hline Case & $\begin{array}{c}\text { Cumulative \% } \\
\text { of Pre-Test Scores }\end{array}$ & $\begin{array}{c}\text { Cumulative \% } \\
\text { of Post-Test Scores }\end{array}$ \\
\hline Case 1 & $87.5 \%$ & $75 \%$ \\
\hline Case 2 & $87.5 \%$ & $81.2 \%$ \\
\hline Case 3 & $81.2 \%$ & $75 \%$ \\
\hline Case 4 & $87.5 \%$ & $87.5 \%$ \\
\hline Case 5 & $81.2 \%$ & $81.2 \%$ \\
\hline
\end{tabular}

instructor could notice the improvements in head nodding and peculiar sounds. He became less aggressive as he started enjoying the sessions and the company of other children. $\mathrm{He}$ scored $87.5 \%$ cumulative scores in the pre-test evaluation and $75 \%$ cumulative scores in the post-test evaluation, which indicates a positive change in the repetitive and stereotypical behaviour of the case.

\section{Case 2:}

A 10-year-old boy had speech impairments and difficulty in verbal communication. He was showing symptoms such as rocking body, head nodding, thumb sucking and shaking body. He initially had very strong resistance and showed no interest in joining the sessions in the beginning. He used to cry during the initial sessions. So, the instructor started giving him the reinforcement such as clapping after each movement. Then in the fifth session, he himself picked one ball and kept it in the bowl and clapped for himself. From that very day, he started getting engaged in the activities. Whenever he was in a good mood, he used to move his head all around. It was not difficult to engage him in the activity with music because he had liking towards music. He also used to follow instructions not only in the session room but also in the class room. The instructor noticed improvement in head nodding and body shaking of the case. He scored $87.5 \%$ cumulative scores in the pre-test evaluation and $81.2 \%$ in the post-test evaluation, indicating a positive change in the repetitive behaviour of the case.

\section{Case 3:}

Head nodding, thumb sucking and making peculiar sounds was evident in this case of 15 -year-old girl. She was fairly participating in activities and following all instructions, but she always left the activities in the middle. She was very lethargic in doing movements. The instructor had to intervene for making the dance moves. She used to make peculiar sounds again and again while dancing also. This case used to repeat her name during the activities. The case started showing progress from the fourth session when she started to move her body by herself without assistance. During these movements, the peculiar sounds were also reduced. She started completing the activities 
towards the end of eighth sessions and could completely follow it by towards the last sessions. She also had inclination towards the song 'Lakdi Ki Kathi' (a famous Hindi rhyme). She scored $81.2 \%$ cumulative scores in her pre-test evaluation and $75 \%$ cumulative scores in her post-test evaluation. This indicates a positive change in the repetitive and stereotypical behaviour of the case.

\section{Case 4:}

A 9-year-old boy had been so stubborn and restless throughout the sessions. He was struggling with head nodding, rocking body, making peculiar sounds and swinging round and round. Immediately after entering the room, he used to remove his shoes and jump on the trampoline. He never followed the instructions in the beginning. The instructor had to intervene for his participation. Moreover, he was much interested in listening to the music and watching the video instead of doing dance movements. However, he started doing ball activity from the eighth session and also started following few instructions; his participation in the activities was very inconsistent and irregular. He was always interested in running away from the room. He scored $87.5 \%$ in the pre-test as well as in the post-test evaluation. Hence, no improvements could be observed in this case pertaining to repetitive and stereotypical behaviours.

\section{Case 5:}

This 11-year-old girl was very rigid, aggressive and stubborn, having symptoms such as rocking body, head nodding, thumb sucking and making peculiar sounds. She was absent minded and never listened to the instructor. She always wanted to sit in the room but never wanted to dance in the beginning of the sessions. The instructor had to intervene her every time to make her move. She was resistant about doing any activity. She used to put everything in her mouth. Despite the reinforcements, this case did not show any improvements. She scored $81.2 \%$ cumulative scores in her pre-test as well as in her post-test evaluation. Hence, a positive change could not be observed in repetitive and stereotypical behaviour of the case.

\section{DISCUSSION}

The study consisted of five participants diagnosed with moderate ASD. Three of the five cases have shown improvement in the stereotypical and repetitive behaviour such as head nodding, making peculiar sounds and rocking body. Hence, the hypothesis that dance movement will bring positive change in stereotypical and repetitive behaviour of children diagnosed with ASD is partially approved. The participants took three to five sessions to adapt the activity and to get connected with others in the group. The findings of the current study are partially in accordance with the findings of Martin (2014), where he assessed the effectiveness of dance movement on children with autism.

Research shows that movement and exercise can spark the growth of new brain cells and facilitate learning (Ratey, 2008). However, the research is more focused on body awareness and sense of self, creativity, leadership and taking initiative in both children and adults (Kalish, 1968; Levy, 1988; Payne, 1990). Nadel and his associates (1999) worked on imitation as a communicative means in infant with autism and found significant correlation between imitation and positive social behaviour and also found imitation as a good predictor of social capacities in children with autism. These findings were in consistence with the similar studies (Dawson \& Adams 1984; Tiegerman \& Primavera, 1981). Older studies have been conducted on imitation, reflection and synchronous movement work in children with autism to cultivate social interactions amongst them (Costonis, 1974). Amongst later studies, one focused on substituting the instructor with humanoid robot (Robins at al., 2004) in which positives effects were observed on responsiveness and social skills of people with autism. Most recent pre- and post-test study aimed to investigate the influence of dance movement on children diagnosed with ASD was conducted on a sample of 45 participants who were given 24 sessions of 1 hour each, twice in a week. The results brought significant changes in the participants including enhancing language and facilitate communication in the children with autism (Souza-Santos, Dos Santos, Azevedo-Santos, \& TeixeiraMachado, 2018).

Another research was conducted to assess the effect of exercycle on repetitive behaviour of children diagnosed with ASD. The exercycle involved both physical as well as mental exercises simultaneously. This research did not give much effective results to the repetitive behaviour of children with autism, hence, suggested for further investigations to observe the effective changes in children (Hanley et al., 2011).

Most of the studies concern common behavioural problems of such cases, such as aggression, self-injurious behaviours and interfering repetitive behaviours (Kay \& Tasman, 1996), and some studies were performed on developing therapeutic relationship (Porter, 2012) in which effectieve changes are observed in response to dance movements and mirroring, which is said to be an effective approach in such cases (Eberhard-Kaechele, 2012; McGarry \& Russo, 2011). 
As the individual scores do not suggest strong difference in the pre- and post-test assessments of all the cases, it will be superlative to conclude that dance movements will bring positive change in stereotypical and repetitive behaviours of children with ASD. In some cases, it may be useful. However, future studies are required pertaining to this domain because the available literature emphasises more on the role of dance movements on social communication, language and other aspects. Stereotypical and repetitive behaviours are very less explored in this context.

\section{CONCLUSION}

The current study explains the positive role of dance movement on stereotypical and repetitive behaviours of children with ASD. It is concluded that stereotypical and repetitive behaviours such as head nodding, rocking body and making peculiar sounds may be improved with dance movements in some cases. However, this facilitation does not provide complete assurance.

\section{LIMITATIONS}

Although the current study has constructive implications, it also has its limitations that can be looked into for further studies. As the current study is a case-based study, the sample used for the investigation was too small for broader generalisations. The study can be replicated in the future on a bigger sample. Owing to the time constraints, the current study could not exceed 15 sessions. Probably, the remaining two cases would have also shown some improvements in the later sessions. Also, the follow-up sessions could not be planned to assess the sustainability of changes. The volume of music was not kept on record. Hence, the current study cannot suggest whether the changes are permanent or temporary.

\section{FUTURE RECOMMENDATIONS}

If this study is to be reproduced, it is recommended to reproduce the study with bigger sample size. Dance movements apart from jumping, zigzag movements, clapping, and touching the ground, feet and shoulders, specific genres of dance with different music genres should be explored. Future studies can be replicated keeping in mind the type of music such as vocal and instrumental along with the language song (in case of vocal).

\section{DECLARATIONS}

We hereby declare that the manuscript entitled "Effect of Dance Movements on Stereotypical and Repetitive Behaviour of Cases with Autism Spectrum Disorder" submitted to Global Psychiatry is the original piece of work performed by Komal Mishra and Nandita Chaube after the ethical clearance. We confirm that the author and the co-author have substantially contributed to the content of the article and have approved the submitted version. We commit to process the article processing fee (currently none) as published by Global Psychiatry on its website on the day of submission.

\section{ACKNOWLEDGEMENTS}

We would like to acknowledge Dr. Binapani Mohapatra, Lecturer in Rehabilitation Psychology \& Head of the Department, and Dr. G Srikrishna, Lecturer in Rehabilitation Psychology of National Institute for Empowerment of Persons with Intellectual Disabilities, Secunderabad, India, for providing permission to access the cases and extending their help in collecting the data.

\section{ETHICAL APPROVAL}

It is also confirmed that the study was conducted after the ethical approval and also maintained the ethical standards.

\section{FUNDING}

The study does not involve any external funding.

\section{INFORMED CONSENT}

The informed consent was obtained from the parents of all the patients and the confidentiality was assured to them. The purpose and procedure of the study were also explained to them.

\section{STUDY REGISTRATION}

Authors take the responsibility of results and have no objection in making this research publicly available for the readers. 


\section{REFERENCES}

Bauman, M. \& Kemper, A.T. (1994). Neuroanatomic observations of the brain in autism. In M.L. Bauman \& T.L. Kemper (Eds.), The neurology of autism (pp.119-145). Baltimore: Johns Hopkins University Press.

Freundlich, B.M., Pike, L.M. \& Vera Schwartz (1989). Dance and Music for Children with Autism. Journal of Physical Education, Recreation \& Dance, 60(9), 50-53.

Bregman, J. \& Gerdtz, J. (1997). Behavioural interventions. In D. Cohen \& F. Volkmar (eds), Handbook of autism and Pervasive Developmental Disorders (second edition, pp. 606-631. New York: Wiley.

Carr, A. (1999). The handbook of child and adolescent clinical psychology: A Cotextual approach. NY: Brunner-Routledge.

Costonis, M. (1978). Therapy in motion. Urbana: University of Illinois Press.

Courchesne, E. (1989). Neuroanatomical systems involved in infantile autism: The implications of cerebral abnormalities. In G. Dawson (Ed.), Autism: Nature, diagnosis and treatment (pp. 234289]. New York: Guilford Press.

Damasio, H. \& Maurer, R.G. (1978). A neurological model for childhood autism. Archives of Neurology,35, 777-786.

Dawson, G., \& Adams, A. (1984) Imitation and social responsiveness in autistic children. Journal of Abnormal Child Psychology 12, 209-26.

Dawson, G. Meltzoff, A.N. Osterling, J., \& Rinaldi, J. (1998). Neuropsychological correlates of early symptoms of autism. Child Development,69, 1276-1285.

Eberhard-Kaechele, M. (2012). Body memory, metaphor, and mirroring in movement therapy with trauma patients. In: Koch SC, Fuchs T, Summa M, et al. (eds) Body Memory, Metaphor and Movement. Philadelphia, PA: John Benjamins, pp. 267-287.

McGregor, E., Swabey, K. \& Pullen, D. (2015). How Often Do You Move? Improving Student Learning in the Elementary Classroom through Purposeful Movement. Open Journal of Social Sciences, 3, 6-10. doi: 10.4236/jss.2015.36002.

Fombonne, E. (1999). The epidemiology of Autism: A Review. Psychological Medicine, 29, 76-786.
Hoeksema, S.N. (2004). Abnormal Psychology. $3^{\text {rd }}$ Edition. McGraw-Hill: NY.

Johnson, C.P., Myers, S.M. \& The Council on Children with Disabilities (2007). Identification and evaluation of children with autism spectrum disorders. Paediatrics, 120, 1183-1215.

Jones, W. \&\& Klin, A. (2009). Heterogeneity and homogeneity across the autism spectrum. The role of development. Journal of America Academy of Child and Adolescent Psychiatry, 48, 471-473.

Kay., J., Tasman., A. (2006). Essential of Psychiatry. England: John Wiley \& Sons Ltd.

Kestenberg, J.S. (1995). Sexuality, Body Movement, and the Rhythms of Development loriginally published as Parents and Children, 1975). Northvale, NJ: Jason Aronson.

Keysers, C. (2011). The Empathic Brain (E-Book). Createspace. (Create Space Independent Publishing Platform, 2011, and e-book).

Koegel, L. \& Kegel, R. (1996). The child with autism as an active communicative partner. In E. Hibbs and P. Jensen (eds), psychosocial treatments for child and adolescent disorders: Empirically based strategies for clinical practice (pp. 553-572). Washington DC: American Psychological Association.

Koehne, S., Behrends, A., Fairhurst, M. T., \& Dziobek, I. (2015). Fostering Social Cognition through an Imitation-and Synchronization-Based Dance/Movement Intervention in Adults with Autism Spectrum Disorder: A Controlled Proof-of-Concept Study. Psychotherapy and Psychosomatics, 85(1), 27-35.

Levy. F. J. (1988). Dance movement therapy - A healing art. Reston, VA: The American Alliance for Health, Physical Education, Recreation and Dance.

Lord, C., Cook, E.H., Leventhal, B.L. \& Amaral, D.G. (2000). Autism Spectrum Disorders. Neuron, 28, 355-363.

Martin, M. (2014). Moving on the spectrum: Dance/movement therapy as a potential early intervention tool for children with Autism Spectrum Disorders. The Arts in Psychotherapy, 41(5), 545-553.

Mash, E.J. \& Wolfe, D.J. (2013). Abnormal and Child Psychology. $5^{\text {th }}$ Edition. China: Wadsworth Cengage Learning. 
Mayes, S.D. \& Calhoun, S.L. (2011). Impact of IQ, age, SES, gender and race on autistic symptoms. Research in autism Spectrum Disorders, 5, 749-57. Doi:10.1016/j.rasd.2010..09.002.

McGarry, L.M. \& Russo, F.A. (2011) Mirroring in dance/movement therapy: potential mechanisms behind empathy enhancement. The Arts in Psychotherapy 38, 178-184.

Minshew, N.J. \& Godlstein, G. (1993). Is autism an amnesic disorder? Evidence from California Verbal Leaning Test. Neuropsychology, 7, 209-216.

Nadel J, Guerini C, Peze A, Rivet C (1999) The evolving nature of imitation as a format of communication. In: Imitation in Infancy, Cambridge University Press, UK.

Oberman, L. M., \& Ramachandran, V. S. (2007). The simulating social mind: the role of the mirror neuron system and simulation in the social and communicative deficits of autism spectrum disorders. Psychological Bulletin, 133(2), 310.

Oliver, C. (1995). Annotation: Self-injurious behaviour in children with learning disabilities: Recent advances in assessment and intervention. Journal of child psychology \& psychiatry, 30, 909927.

Osterling, J. \& Dawson, G. (1994). Early recognition of children with autism.: A study of first birthday home videotapes. Journal of Autism and Developmental Disorders, 24, 247-257.

Ozonoff, S. (1995). Executive function impairments in autism. In E. Schopler \& G. Mesibov (Eds.), Learning and cognition in autism (pp. 199-220). New York: Plenum Press.

Ozonoff, S., St rayer, D.L. McMahon, W.M., \& Filloux, F. (1994). Executive function abilities in autism and Tourette syndrome: An information processing approach. Journal of Child Psychology And Psychiatry, 35, 1015-1032.

Payne, H. (1990). Creative movement and dance. Oxfordshire, UK: Winslow Press.

Porter, K. A. (2012). Dance / Movement Therapy and Autism : A Case Study. Theses.

Retrived on $16^{\text {th }}$ April 2020 from https://www.semanticscholar.org/ paper/Dance\%2FMovement-Therapy-and-Autism\%3A-A-CaseStudy-Porter/50da38da699d73b7fca62555f30e7b2102a3a750
Prior, M. \& Hoffman, W. (1990). Brief report: Neuropsychological testing of autistic children through an exploration with frontal lobe tests. Journal of Autism and Developmental Disorders, 20, 581590.

Ratey, J.J. (2008). SPARK: The Revolutionary New Science of Exercise and the Brain. New York: Little, Brown.

Robins, B., Dautenhahn, K., Boekhorst R., \& Billard, A. (2004). Effects of Repeated Exposure to a Humanoid Robot on Children with Autism. In: Keates S., Clarkson J., Langdon P., Robinson P. (eds) Designing a More Inclusive World. London: Springer.

Rogers, S. \& Pennington, B. (1991). A theoretical approach to the deficits in infantile autism. Development and Psychopathology, 3, 137-162.

Smith, I.M. \& Bryson, S.E. (1994). Imitation and action in autism: A critical review. Psychology Bulletin, 116, 259-273.

Smith, T. (1993). Autism. In T. Giles (ed.), Handbook of effective psychotherapy (pp. 107-134). New York: Plenum.

Souza-Santos, C., Dos Santos, J. F., Azevedo-Santos, I., \& TeixeiraMachado, L. (2018). Dance and equine-assisted therapy in autism spectrum disorder: Crossover randomized clinical trial. Clinical Neuropsychiatry, 15(5), 284-290.

Teixeira-machado, L. (2015). Dance therapy in autism: A case report. (02238312), 205-211. Retrived from https://doi. org/10.590/1809-2950/11137322022015

Tiegerman, E., \& Primavera, L. (1981). Object manipulation: An interactional strategy with autistic children. Journal of Autism and Developmental Disorders, 11(4), 427-438.

Kalish, B. (1968). Body movement therapy for autistic children. In: Proceeding of the 3rd Annual Conference of the American Dance Therapy Association, USA: Madison, Wisconsin.

Anderson-Hanley, C., Tureck, K., \& Schneiderman, R.L. (2011). Autism and exergaming: effects on repetitive behaviors and cognition. Psychology research and behavior management, 4, 129 $-137$. 